\title{
Real-Time Implementation and Analysis of Crop-Field for Agriculture Management System based on Microcontroller with GPRS (M-GPRS) and SMS
}

\author{
Vitthal S Saptasagare \\ Second Year Student M.Tech, Dept of CSE \\ Canara Engineering College, Mangalore
}

\author{
Basappa B Kodada \\ Asst. Professor, Dept of CSE \\ Canara Engineering College, Mangalore
}

\begin{abstract}
Modern agriculture needs tools and technologies that can improve production efficiency, product quality, postharvest operations, and reduce their environmental impact. Automation in agriculture brings about a fundamental contribution to what is now known as precision agriculture (or precision farming). The real-time environmental parameter which makes a continuous impact on the crop from cultivating till cutting it. Such as soil moisture, temperature, water level of the tank and ph of soil. The proposed system has several types of sensors deployed in the crop field area. It captures the physical phenomenons as mentioned above. The sensed data from various sensors goes to the central Global System for Mobile communication (GSM) node. From that the sensed data is given to the personal computer, which is used by a farmer.
\end{abstract}

\section{Keywords}

GSM Modem with GPRS, Sensors, PIC Microcontroller, LCD Display and Relay

\section{INTRODUCTION}

The biggest and oldest area for research as well as for improvement is agriculture field. A definition of precision agriculture may be the following: the technique of applying the right amount of input (water, fertilizer, pesticide, etc.) at the right location and at the right time to enhance production and improve quality, while protecting the environment. Sensors are the hopeful device for precision agriculture [3]. By forming sensor network we can make good monitoring system in the agriculture field. In Agriculture land the farm environment condition such as temperature, soil moisture content, water level and ph of soil are continuously monitored by sensors. A GSM modem which has GPRS feature that provides information over long transmission in terms of kilometers, such as it eliminates the existing a limited range of few meters and it is also interfaced with the PIC16F877A microcontroller [2][4]. The system continuously displays values and informs user about any abnormal conditions like less moisture content and temperature rise, even concentration of ph and low water level in the tank via SMS from the system to the farmer's mobile and actions are taken accordingly by the farmer [1].The system has automatic and manual mode. The set points may be varied manually according to the environment condition to satisfy the given conditions for the crop land. Field conditions were sitespecifically monitored by in-field sensor stations distributed across the field. The values are based on a maximum and minimum like threshold values from field station are then wirelessly transmitted to a base station by using GPRS technology, which adds new feature to the GSM node.

\section{LITERATURE REVIEW}

Kshitij Shinghal et. Al. proposed "Wireless Sensor Networks in Agriculture: for Potato Farming", 2010. This paper proposed how WSN nodes can also be effectively employed to collect data of soil water availability, soil compaction, soil fertility, biomass yield, plant water status, local climate data, insect-disease-weed infestation, crop yield, etc [5].

K.Nirmal Kumar and R.Prapakaran present "Zigbee Wireless Sensor Network Technology study for Paddy Crop Field Monitoring", 2011. Analysis about real time readings of temperature sensor deployed in paddy crop field with Xbee nodes and Xbow nodes. Results show that Zigbee wireless sensor network is resourceful for paddy crop field monitoring. But Zigbee technology limits control signal transmission [3].

Purnima and S.R.N. Reddy present "Design of Remote Monitoring and Control System with Automatic Irrigation System using GSM-Bluetooth", June 2012. This paper gives a review of remote control and monitoring systems based on existing technologies and a GSM-Bluetooth based remote control and monitoring system with automatic irrigation system is proposed [1].

V. Ramya and B. Palaniappan and Boby George proposed "Embedded System for Automatic Irrigation of Cardamom Field using Xbee-PRO Technology", September 2012. Embedded system for automatic irrigation of a cardamom field offers a potential solution to support sitespecific irrigation. Also shows how to integrate all the hardware components according to particular task [2].

\section{METHODOLOGY}

There are two types of designing methods, one is Top-down method and the other is Bottom-up method. This work adopts the Top-down method. The design is a solution, the translation of requirements into the way of meeting them. The design will determine the success of the system. Based on the proposed system objectives, the major modules are identified and the operations to be carried out are determined. In the design phase of the system the data flow diagrams, flowcharts, data base tables, inputs, outputs and screen are designed by using all the necessary fields in a compact manner. 


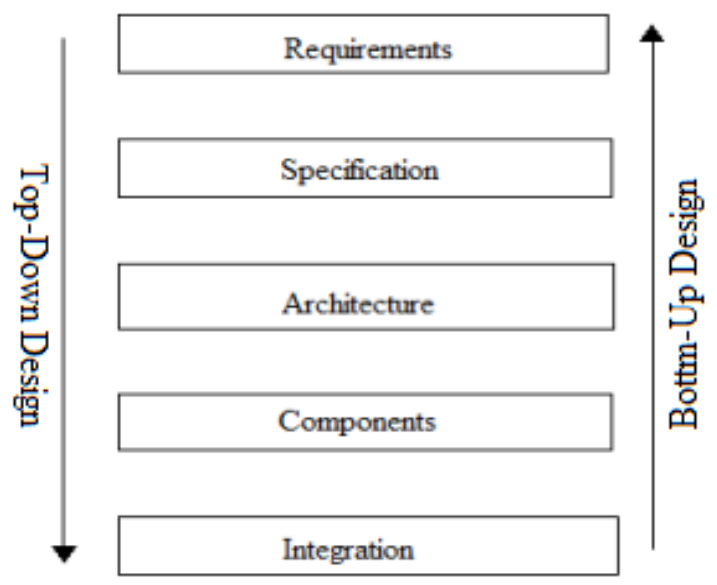

Figure 1 Major levels of abstraction in design process

\subsection{Requirement Analysis}

The requirement phase is the first level in which the functional and non functional requirements like performance cost, physical size and weight and power consumption for developing the proposed system were analyzed.

\subsubsection{Functional Requirements}

$>$ Sensing requirements like Temperature, Moisture of field, and water level of Water Tank.

$>$ Alarm Monitoring requirements [If water level is very low].

$>$ Signal conditioning requirements.

$>$ Actuator control Requirements [Relay ON/OFF].

$>$ Man-Machine interaction Requirements [Select automatic and manual mode for irrigation].

$>$ Data Collection Requirement [Maintain database about sensing data].

\subsubsection{Non-Functional Requirements}

Typical non-functional requirements include performance of agriculture management system process, cost of $\mathrm{H} / \mathrm{W}$, physical size of component also weight and how the power may be consumes for the field station.

\subsection{Specification Level}

The specification level reflects the requirements specified in the first level, it says only what the system does and not how to implement. In this proposed work the specification of the agriculture management system includes:-

$>$ Data received from GSM Modem

$>$ User interface

$>$ Sensor data to the Microcontroller

$>$ LCD Display

$>$ Message Delivery

\subsection{Architecture Level}

The hardware of the system mainly includes an 8-bit PIC16F877A microcontroller chip, a GSM modem with GPRS facility and RS232 interface. The microcontroller is interfaced with different sensors for controlling different applications. Moisture sensor, Temperature sensor and Water level sensor is used to sense the moisture value of soil temperature of field water level of tank is in analog form is converted to digital using A/D converter [1] [2]. EEPROM is used for recording the data provided by the sensors. It provides this data to the microcontroller for analysis when requested and in emergency conditions depending upon this data an SMS is send to the farmers mobile. Even routinely recorded these data can help in making remote and control module of automatic irrigation system. GPRS provide distance based control over agriculture parameters. Real time clock helps in proper time-to-time recording of data. The measured values and the status of the devices are displayed on the LCD. The GSM modem with GPRS technology which are the most important part of this system are interfaced with the microcontroller using RS232 interface. It acts like an interface between the controller and GSM network. The GSM Modem must have a SIM (Subscriber Identity Module) card to make the network identify the user. The microcontroller communicates with the GSM modem using the AT commands [1]. These AT commands are used to send and receive SMS. The programming code for the microcontroller is written in some high level language. The use of a PC as a monitoring and base station provides for control of devices which are located far away from farmer's house, in the proposed system it is an important part of the internet based systems. The Architecture level is a plan for overall system that will be used to design the components that make up the architecture. The system architecture further refined in to Hardware architecture to ensure all specifications. The hardware architecture is shown in figure 2. It shows the components required to build the system. The architecture should satisfy the functional and non functional requirements.

Figure 2 shows the hardware architecture in which the sensors and GSM modem send the signals to the base station, the base station process the signal and send the control signals to the field station and then switches the relay according to the irrigation conditions for ON/OFF the water pump [1]. The field sensor signals such that soil moisture and Temperature sensor values are fed to the microcontroller through the GSM modem transmitter and receiver using UART. On the other side base station receives the data from field through GPRS and checks whether the limits are exceeding the set point or not.

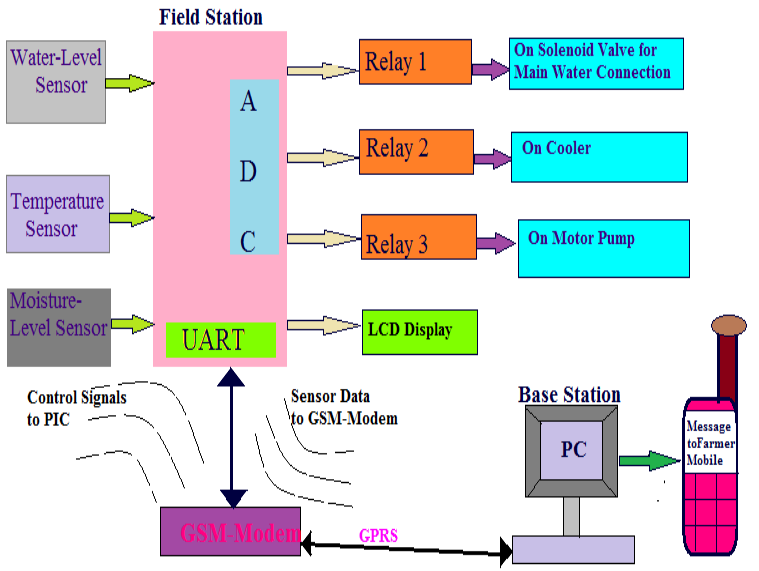

Figure 2 Hardware Architecture of Proposed System

We can manually adjust the set points according to the climate to provide proper irrigation to different aged and different areas of farm land. Base station also maintains the database and displays the current sensor readings.

\subsection{Component Level}

The Component level involves in designing the hardware and software components. 


\subsubsection{Temperature Sensor}

The LM35 series are precision integrated-circuit temperature sensor. The LM35 is rated to operate over a $-55^{\circ}$ to $+150^{\circ} \mathrm{C}$ temperature range. The proposed system maintains the temperature range between $24^{\circ} \mathrm{C}$ to $35^{\circ} \mathrm{C}$. This value manually is changed according to the seasonal temperature using the manual mode.
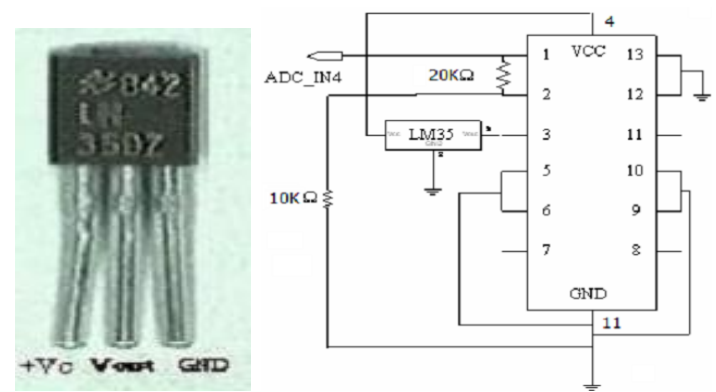

Figure 3 LM35 Temperature Sensor with circuit diagram

\subsubsection{Soil Moisture Sensor}

Grid-like resistance-type sensor senses the moisture on vegetation from $0 \%$ (dry) to $100 \%$ (wet). The sensor is a circuit board with interlacing fingers. The proposed system uses the moisture range in between $50 \%$ to $70 \%$, this is normal condition. It can be changed manually whenever we want.

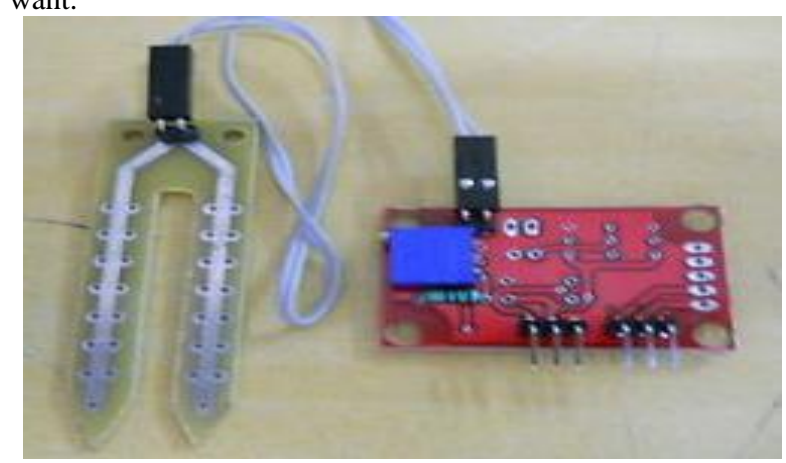

Figure 4 Soil Moisture Sensor

\subsubsection{Relay}

In this proposed work relay is used for connecting the solenoid valves to microcontroller. When the ignition key is turned all the way to the "start" position, it allows electricity to flow to the starter solenoid (relay) which then connects the battery to the starter motor.
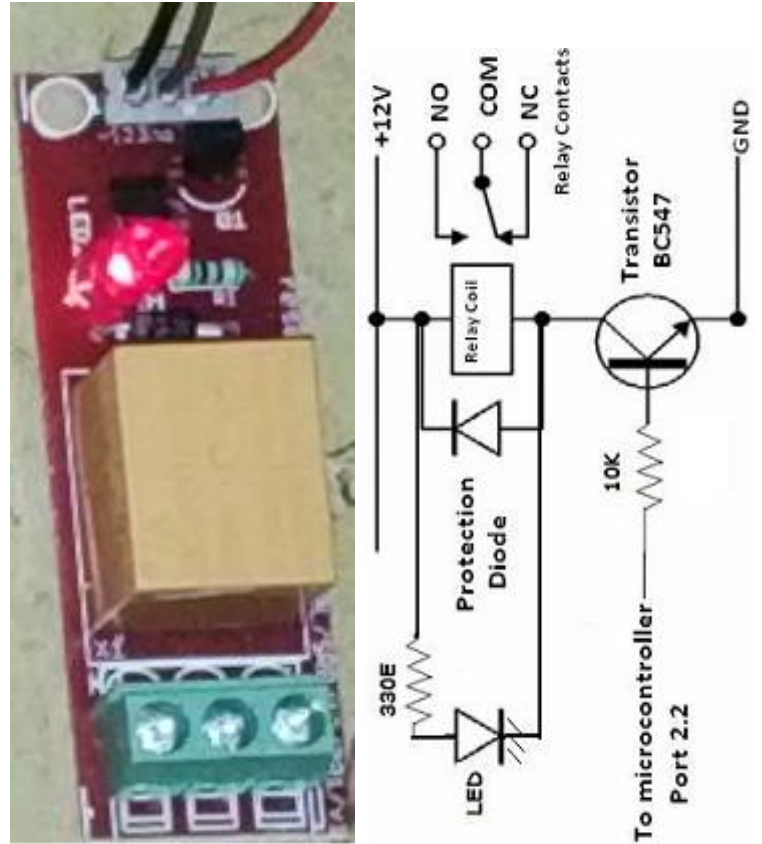

Figure 5 Relay with Circuitry

\subsubsection{LCD}

LCD is used for displaying the parameters like water level, temperature and soil moisture in the agriculture field. It is a back-Lit LCD display 480x360[16x2]. Figure 6 show that the LCD display shows the values of the sensors.

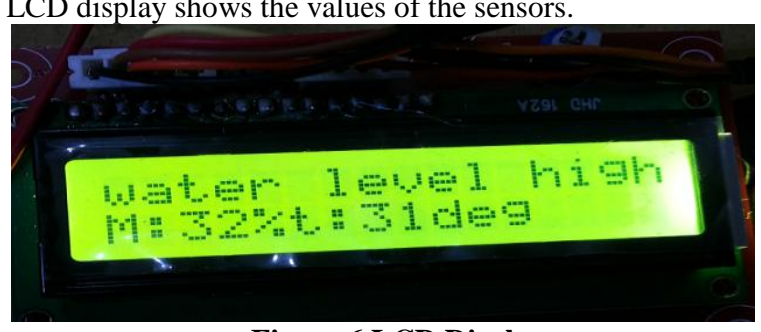

Figure 6 LCD Display

\section{IMPLEMENTATION 4.1 Integration Level}

The System Integration is not simply plugging everything together but also finding the bug at this stage. In Embedded system, the system integration is a challenging task, since it is difficult to find why things are not work properly. Due to limited facility at the target system, we have to go to host system for testing. This proposed system has two modules, one is Field station and the other is Base station. Figure 7 shows the field station and figure 8 shows the base station. Field station sensed the parameters like Temperature, Soil Moisture and Water Level of tank from different areas of the plantation and display those parameters in LCD. Then these parameters are sent to the base station. The base station analyzes these parameters with set points for proper irrigation. 


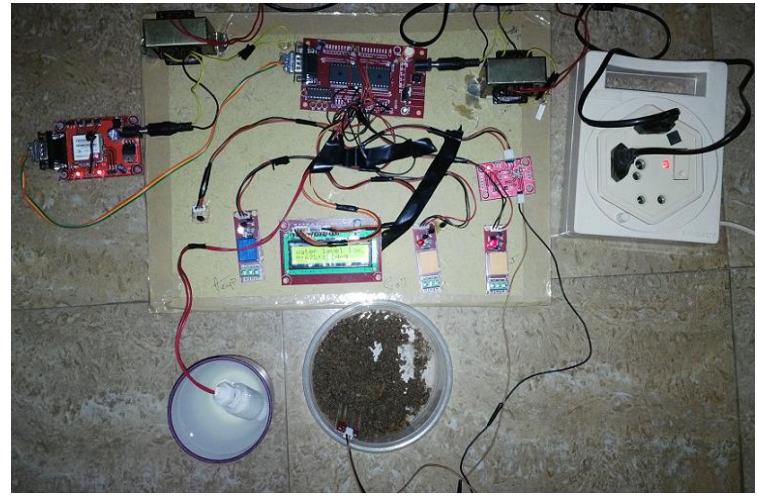

Figure 7 Connection of the system at field station

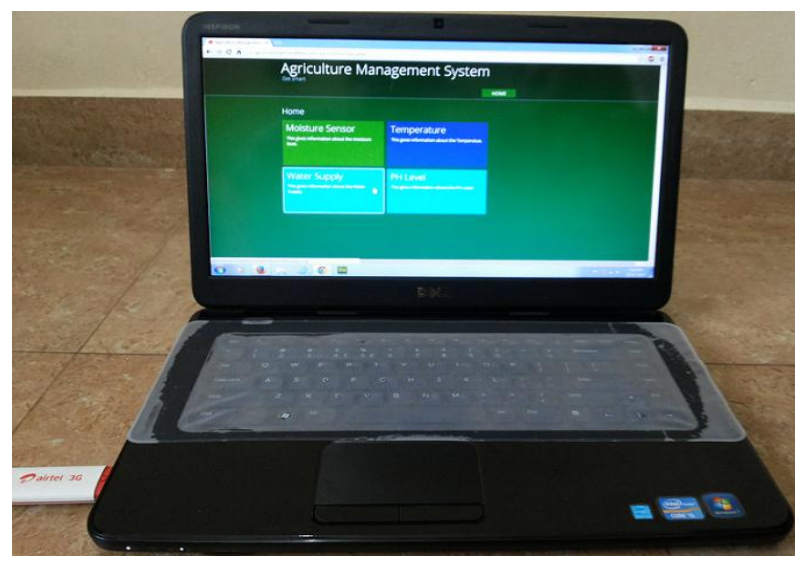

Figure 8 Base station

\section{RESULTS AND ANALYSIS}

The proposed work has a number of results to be considered. The front end which is shown in figure 8 also displays the gauge readings of the parameters such as Temperature, Moisture and PH value of soil. And the status of main valve also displayed.

The main page of user contains following:-

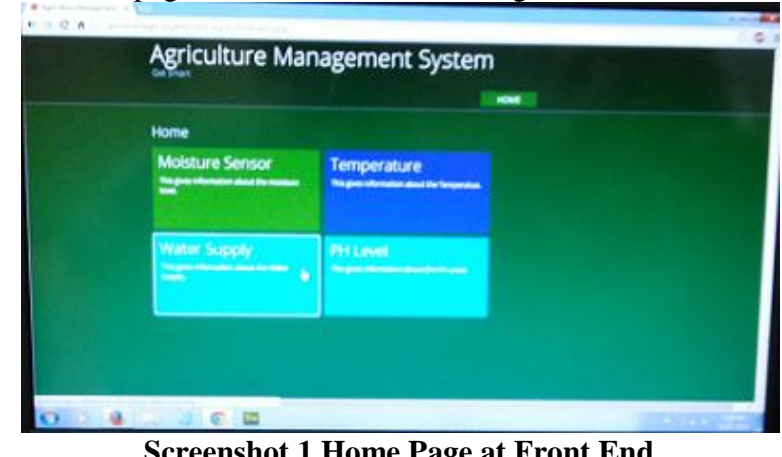

Screenshot 1 Home Page at Front End

\section{1) Moisture sensor}

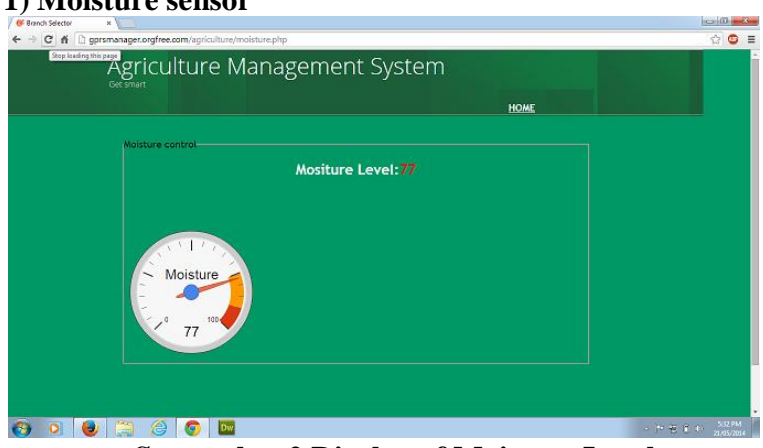

Screenshot 2 Display of Moisture Level
Moisture sensor page contains graphical and gauge representation of the moisture value of the particular crop which is been evaluated.

\section{2) Temperature sensor}

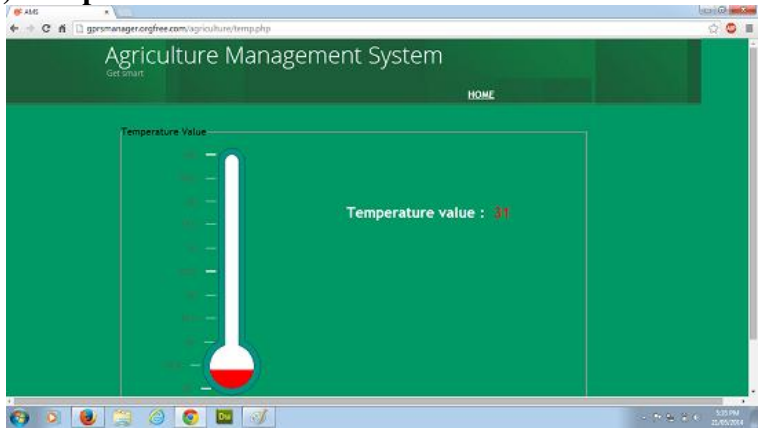

Screenshot 3 Display of Temperature Value

Temperature sensor continuously senses the field data and sends it to the base station and also mercury increases with temperature as shown in gauge display.

\section{3) Water level sensor}

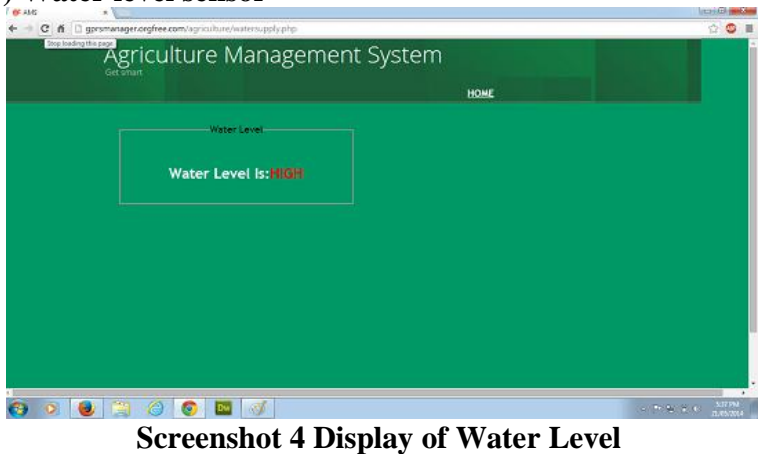

For this magnetic level sensor is used. The principle behind magnetic, mechanical, cable and other float level sensors involves the opening or closing of a mechanical switch, either through direct contact with the switch, or magnetic operation of a reed. With magnetically actuated float sensors, switching occurs when a permanent magnet sealed inside a float rises or falls to the actuation level.

\section{4) PH level sensor}

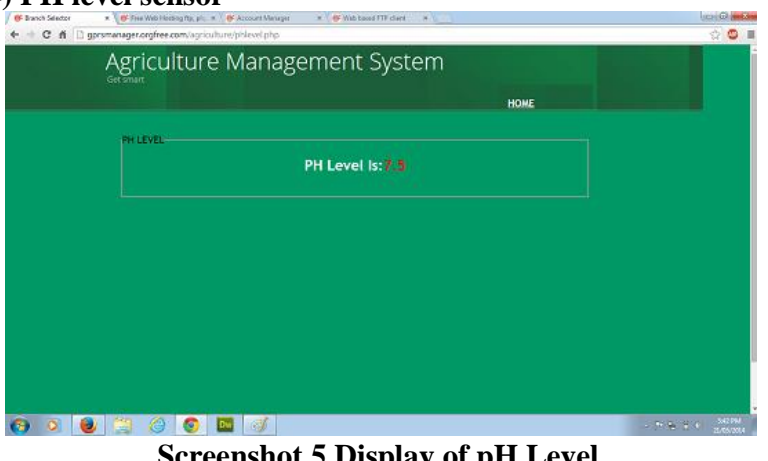

Screenshot 5 Display of pH Level

$\mathrm{PH}$ level sensor page gives the current $\mathrm{PH}$ level of the soil based on the soil moisture value. If it increases $\mathrm{PH}$ value also raises due to more acidic substances dissolves in soil. 
Moisture/Depth of sensor

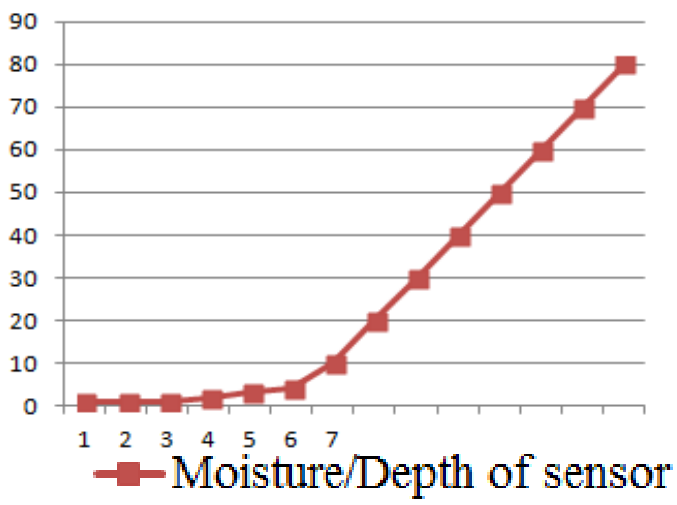

Figure 9 Increases in Moisture Value with Depth of Sensor The depth of water level in the soil is defined as the ratio of the depth of sensor in soil and moisture value of soil having is expressed as an inch. The application efficiency of a well designed irrigation system will be between 60 and $80 \%$. To increase the application efficiency up to $70 \%$ for the crop the amount of water applied should be:

$$
\begin{gathered}
\text { Depth of water }=\frac{\text { Depth of sensor }}{\text { Moisture value }} \\
\text { It can be represented as } \sum=\underline{\underline{\epsilon}} \\
¥
\end{gathered}
$$

Where, $€$ (Depth of sensor) $=1$ inch and

$¥($ moisture value $)=0.32 \%$. Then $\sum($ Depth of water in soil $)=$ 3.12 inch.

$$
\text { Therefore, } ¥=\underline{32}=0.32 \%
$$

Soil moisture level is a measure of how strongly water is held by the soil. All plant performance is closely related to the amount of tension the plant has to exert to move water from the soil into the plant roots.

\section{Moisture/Ph value}

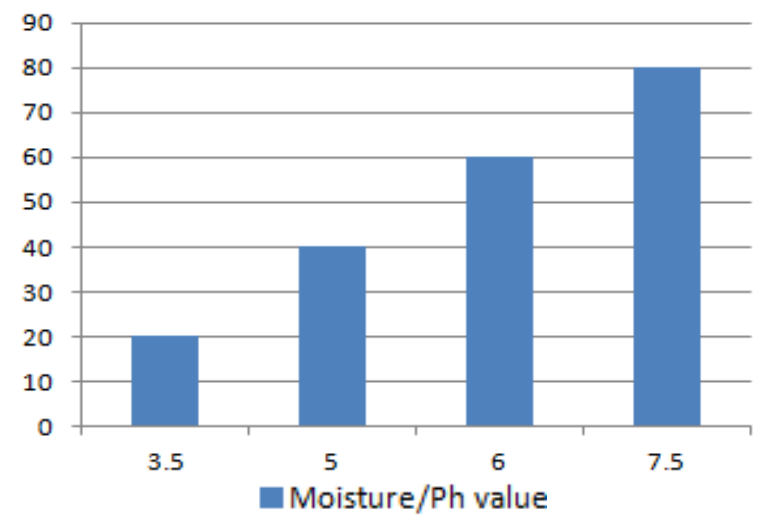

Figure 10 Increases in pH Value with Moisture Value

Table 1 pH Value Based on Soil Type

\begin{tabular}{|c|c|c|}
\hline Soil Type & Soil Moisture & PH Value \\
\hline \multirow{3}{*}{ Poor } & $30 \%$ & 3.5 \\
& $50 \%$ & 5 \\
& $70 \%$ & 6 \\
\hline \multirow{3}{*}{ Normal } & $30 \%$ & 3.5 \\
& $50 \%$ & 5.5 \\
& $70 \%$ & 7.5 \\
\hline \multirow{2}{*}{ Acidic/Alkaline } & $30 \%$ & 5 \\
& $50 \%$ & 7.5 \\
& $70 \%$ & 8.5 \\
\hline
\end{tabular}

The $\mathrm{pH}$ level of soil increases if soil moisture value increases. Due to dissolving of acidic substances in soil with flooding water to it. According to some standard observation with preparing concentrated chemicals mixed in soil it varies as follows. On the standard scale on International Society of Science $\mathrm{Ph}$ reads from 1-14. In between 6-7.5 is normal in Human stomach HCL range is also same.

Table 2 Real Values from Sensor Readings

\begin{tabular}{|c|c|c|}
\hline $\begin{array}{c}\text { Temperature } \\
\text { value }\end{array}$ & Moisture value & PH value \\
\hline 24 & 32 & 3.5 \\
\hline 27 & 40 & 4 \\
\hline 29 & 46 & 5 \\
\hline 31 & 53 & 6 \\
\hline 33 & 61 & 6.5 \\
\hline 35 & 75 & 7.5 \\
\hline 32 & 80 & 8 \\
\hline 30 & 95 & 8.5 \\
\hline 28 & 90 & 9 \\
\hline 26 & 81 & 9.5 \\
\hline 25 & 73 & 10 \\
\hline & 65 & 9.3 \\
\hline & 50 & 9 \\
\hline
\end{tabular}

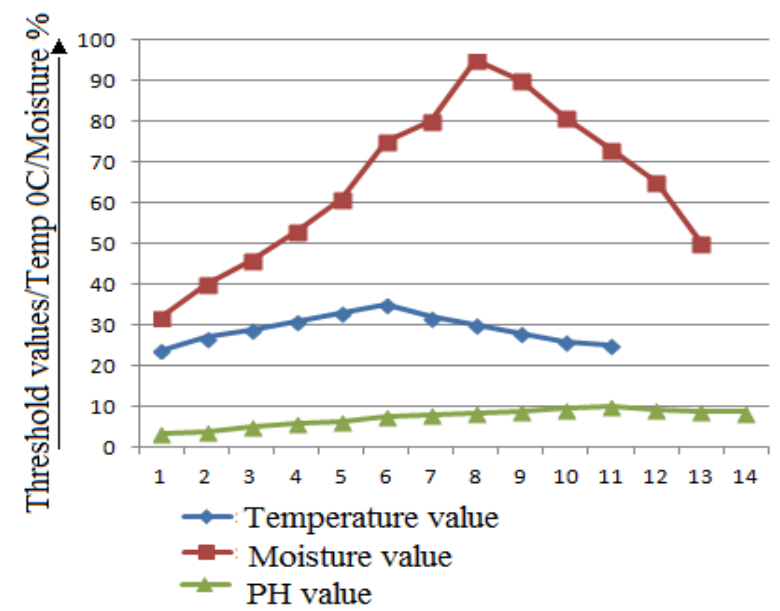

Figure 11 Variations in Different Parameters with Threshold Values

The above table takes all the experimental values from different readings with respect temperature, soil moisture and ph level. The plot drawn below table indicates the values that reach peak value and comes down slowly according to condition.

\section{CONCLUSION}

Agriculture Management system is expected to play an important role in improving farming activities. During the past years, sophisticated farm management systems have emerged to replace outdated complex and monolithic farm systems and software tools. The latest trend is to enable these management systems to operate over the Internet. In this proposed work we attempt to enable a farmer to step into a new reality, where he becomes an actual "node in an agricultural worldwide web". He as a user can monitor his farm land without actually being there through web. And also he will get timely alert messages on his phone if any of the sensor value deviates from the maximum and minimum value 
permitted for the particular crop so that he can take proper action.

\section{FUTURE SCOPE}

In future it is to be expanded as by making a small set of box that is to be fixed in starter of electric pump set and sensors are fixed with it. It has a SIM card through this user can give a missed call the pump will ON/OFF automatically. Also the work carries with by using solar panels instead of battery for power supply. It reduces the cost and solves the problem of abnormal voltage conditions.

\section{ACKNOWLEDGMENTS}

Any Achievement, be in scholastic or otherwise does not depend solely on the Individual effort but on the guidance, encouragement and co-operation of intellectuals. With profound sense of gratitude and respect, I thank my internal guide Basappa B Kodada, Asst. Prof. Department of Computer Science and Engineering, Canara Engineering College, Mangalore for their valuable guidance and support towards the development of the template.

\section{REFERENCES}

[1] Purnima, S.R.N. Reddy, Department of Electronics \& Communication \& Computer Science IGIT, GGSIP University, Delhi, India. "Design of Remote Monitoring and Control System with Automatic Irrigation System using GSM-Bluetooth" International Journal of Computer Applications (0975 - 888) Volume 47- No.12, June 2012.

[2] V. Ramya, B. Palaniappan, Boby George, Dept of Computer Science and Engineering Annamalai University Chidambaram, Tamilnadu, India. "Embedded System for Automatic Irrigation of Cardamom Field using Xbee-PRO Technology" International Journal of Computer Applications (09758887) Volume 53-No.14, September 2012.
[3] K.Nirmal Kumar, R.Prapakaran, Pervasive Computing Technologies, Centre for Convergence Technologies Anna university of Technology, Thiruchirappalli, India." Zigbee Wireless Sensor Network Technology Study for Paddy Crop Field Monitoring" International Conference on VLSI, Communication \& Instrumentation (ICVCI) 2011Proceedings published by International Journal of Computer Applications ${ }^{\circledR}$ (IJCA).

[4] B. Sudharsan, R. Mohanasundaram, II-ME-Embedded System Technologies, Tiruchengode, Namakkal, Tamilnadu, India. "Observing And Control Of Agricultural Parameters By Using Wired/Wireless Networking Infrastructure" International Journal of Advanced Research In Technology, ISSN NO: 6602 3127, IJART, Vol. 2 Issue 2, 2012, 170-176.

[5] Kshitij Shinghal, Dr. Arti Noor, Dr. Neelam Srivastava, Dr. Raghuvir Singh, Academic Advisor, Shobhit University, Merrut, India. Department of E\&C Engg., Institute of Engineering \& Technology, Lucknow, India. "Wireless Sensor Networks In Agriculture: For Potato Farming" International Journal of Engineering Science and Technology Vol. 2(8), 2010, 3955-3963.

[6] G.Gaderer, P. Loschmidt, and A. Mahmood, "A novel approach for flexible wireless automation in real-time environments" in Proc. IEEE Int. WFCS, Dresden, Germany, May 21-23, pp. 81-84, 200.

[7] Natural Capitalism Solutions, prepared for boulder county parks and open spaces by: "Sustainable Agriculture Literature Review". For more www.BouldercCountryOpenSpace.Org, March 2011.

[8] Robert W. Sebesta, "Programming the World Wide Web" Pearson Education, ISBN 978-81-317-2417-0. 